Japanese Psychological Research

1983, Vol. 25, No. 3, 119-129

\title{
A longitudinal study of learning process of duration estimation in young children
}

\author{
FUMIKO MATSUDA \\ Hiroshima IVomen's University, Minami-ku, Hroshima 734 \\ MICHIHIKO MATSUDA ${ }^{1}$ \\ Kochi Medical Sofool, Nankoku, Kochi $781-51$
}

\begin{abstract}
Learning processes in accuracy of duration estimation were examined several times by the response duration schedule at about semiannual intervals on the same children as they grew from three to six years old. The apparatus was a picture of a boy moving along a path with a constant speed, the start-and-stop being controlled by a button. The subject was instructed to push the button exactly for the duration required for the boy start moving and stop at a goal which took $10 \mathrm{~s}$. The moving boy and the goal were hidden from the subject's view, and only after each trial he received visual and verbal fecdbacks. Almost all children over three years eight months of age could succssfully carry out the task. Numbers of trials to reach the criterion and errors in the response durations decreased with age.
\end{abstract}

Key words: duration estimation, young children, response duration schedule, longitudinal study, feedback.

Several studies have indicated by various methods that children are inferior to adults in accuracy of time estimation and that this tendency increases as age decreases.

Using the method of verbal estimation, Axel (1924) and Crawford and Thor (1967) examined time estimation in children and adults. Smythe and Goldstone (1957) examined it by a modified method of limits. These findings suggest children make rapid progress in accuracy of time estimation from ages six to 11 years and after that show only a little change until adulthood. But it is not clear whether children's inaccuracy is due to their failure to understand and use conventional time concepts or their inability to perceive time accurately.

Some investigators examined time es-

1 The authors express their deep gratitude to Professor A. Kawahara and Assistant Professor $\mathrm{H}$. Miyazaki, Hiroshima University, for fabricating the main parts of the apparatus. Special thanks are also due to Mr. P. M. Clayburn, lecturer in English at Hiroshima Women's University, for his critical reading from the point of English style.

Calculations were mainly done at Computer Center, Kyushu University. timation in children under situations where they were not required to make use of conventional units of time, using a constant method by paired comparisons (Flückiger, 1975) and the reproduction method (Fraisse \& Orisini, 1958; Matsuda, 1965a; Matsuda \& Matsuda, 1974, 1976; Orsini, 1958). These investigations indicated that, when using no conventional time units, the time estimation was possible for relatively younger children and the tendency to inaccuracy was less striking. But in these cases, even the youngest children were five years old. Richards (1964) found that reproduced durations for standards of 2 to $4800 \mathrm{~s}$ were completely inaccurate in a 4-year-old child but considerably accurate in a 6 year-old.

It would be easily assumed that accuracy improves by giving feedback about the estimated time, that is, that time estimation can be learned.

Fraisse and Orsini (1958) and Orsini (1958), who used the reproduction method to examine the learning of duration estimation in children aged five to 10 and 
in adults, gave the subject after each reproduction one of three verbal reinforcements together with one of thrce lights which indicated whether the reproduced interval was too long, too short or accurate $(30 \pm 5 \mathrm{~s})$. The subjects, especially the young children, showed rapid progress during 10 trials with this feedback. Crowder and Hohle (1970), who also examined the learning process in children aged five to 10 by the reproduction method, used an elabolated visual feedback to transform duration into spatial distance besides a verbal reinforcement. All subjects showed a smooth progress during 15 trials with the feedback, but except for 5-year-old children subjects who were not given these feedbacks showed similar progress. In these experiments the effectiveness of the feedback is not clear, because learning is expected to occur even without feedback by comparing a reproduced time of a given trial to the standard time of the next trial.

Using a modified method of limits, Smythe and Goldstone (1957) examined estimations of $1.0 \mathrm{~s}$ in children aged six to 14 and in adults, as previously stated. Five presentations of a precise $1 \mathrm{~s}$ after 20 trials without feedback were effective to increase the accuracy of duration estimation in children over eight years old and adults but ineffective in children of six and seven.

These findings suggest that preschool children could not learn to estimate the standard time interval simply from repeated observations of it.

Using a modified method of production, Friedman (1977) examined the effects of feedback on estimation of $15 \mathrm{~s}$ in children aged $2 \frac{1}{2}$ to $5 \frac{1}{2}$ and insisted that it was possible to conduct research on time estimation at an early age if the procedures are relatively short and of interest to the young child. However it seems quite doubtful to the present investigators that his procedure was attractive for the young child and that the subject really under- stood his task.

Weisberg and Tragakis (1967) and Weisberg (1970) examined timing performance in children aged one to three by the differential reinforcement of low rates of response (DRL) to 10 and $18 \mathrm{~s}$ schedules with snack reinforcement. In Stein and Landis (1978), 5- and 7-year-old children were reinforced according to a DRL 5 s schedule with candy. Pouthas (1981) also examined capacity of adapting to intervals of 1 to $15 \mathrm{~s}$ by the DRL schedule in children aged two to four, using a ingenious cognitive reinforcement corresponding to the child's interest. Results of these investigations indicated that it was possible for the very young child to adapt in some degree to these time intervals by the DRL schedules but that it was considerably more difficult as the subjects were younger.

In these experiments, the interresponse time was relevant to the temporal conditioning and, to obtain reinforcement, subjects had to learn to refrain from emitting the reinforced response for the period of time defined by the DRL requirement. Besides, there were no upper limits of interresponse time in regard to reinforcement.

The purpose of this study was to examine systematically development of the learning process of time estimation in young children by another schedule. A combination of the reproduction method and the response duration schedule was used. That is, unlike the reproduction method the standard duration was demonstrated only at the first experimental trial in order to remove a kind of informative feedback effect of the standard duration. It is almost impossible to instil a strong drive into young children, to give them a strong reinforcement and to continue several hundred trials as conducted in experiments using animals. Therefore, the standard duration was demonstrated at the first experimental trial in order to make young children learning easily, un- 
like the response duration schedule. In any case, as it is the response duration that was relevant to the temporal conditioning, the subject's behaviors during the time estimation may be less various and uncontrolled than in the DRL schedule.

In the experiment in this study, besides verbal feedbacks, visual feedbacks transforming duration into spatial distance were used. These were elaborated so as to be concrete, familiar and attractive for young children.

Longitudinal investigations had not yet been carried out in this problem area. Because of large individual differences in the time estimation in young children, such a study may be useful. In this study the same young children were used as subjects at intervals of about six months.

\section{Method}

Apparatus. The apparatus used is shown in Fig. 1. A runner was mounted on a horizontal driving shaft at a distance of $150 \mathrm{~cm}$ from the subject. The runner moved from left to right in $2.93 \mathrm{~cm} / \mathrm{s}$ while the experimenter or the subject was pushing their respective electric button connected with a control circuit. While neither buttons was pushed, the experimenter could freely slide the runner on the driving shaft by hand. The longest path-length of the runner was $90.5 \mathrm{~cm}$. These main parts of the apparatus were made by Kawahara and Miyazaki (1980). Two electric stopwatches (TKK Digital Stop Watch, Model No. 413) were connected with the control circuit. The one which worked while the runner was in motion was used to measure the response duration, the other which worked while the runner was stopped was used by the experimenter to make the intertrial interval as constant as he possibly could. In the present experiment we tried to set the intertrial interval at $12 \pm 1 \mathrm{~s}$ but it often grew longer because of using young children as subjects. Catania (1970) showed that the intertrial interval affected temporal judgments in some cases.

A picture of a walking boy $2.93 \mathrm{~cm}$ wide was fixed on the runner. At a point on the driving shaft stand a picture of a house was fixed. The house was also $2.93 \mathrm{~cm}$ in width, so that when the runner was just behind the house the subject could not see the boy. The house was at

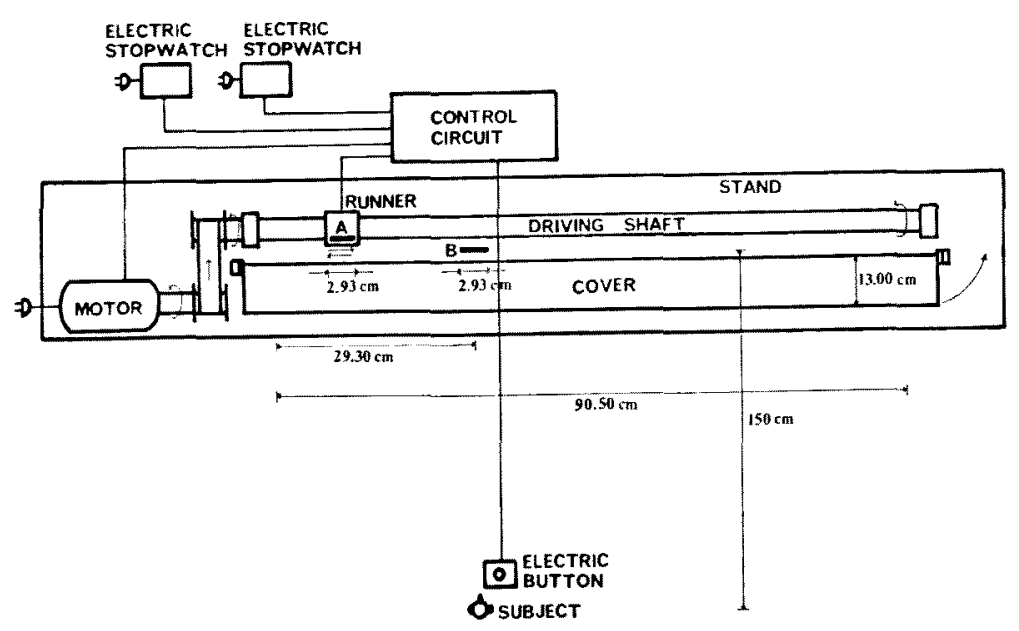

Fig. 1. Apparatus.

A: A picture plate of a boy $(10.00 \mathrm{~cm}$ in hight $\times 2.93 \mathrm{~cm}$ in width).

B: A picture plate of a house $(11.00 \mathrm{~cm}$ in hight $\times 2.93 \mathrm{~cm}$ in width), 
the point where the runner would be just behind it $10 \mathrm{~s}$ after starting from the left end of the driving shaft.

A metal cover was also fixed to the stand. When the cover was opened the subject could see both the boy and the house but when it was closed he could see neither. It was manipulated by the experimenter's hand.

Because all parts of the apparatus except the boy, the house and the cover were hidden by black cloth, there were no attractive and meaningful things for young children except these parts of the apparatus and the electric button next to their hands.

The subject could see the face of experimenter when the cover was opened, but not when it was closed.

Procedure. First, opening the cover, the experimenter made the subject understand operatively that while he was pushing the button the boy was running to the house and that as soon as he stopped pushing it the boy stopped running. Then the experimenter returned the runner to the starting point and asked the subject to push the button to move the boy and then to stop pushing it just when the boy entered the house. This preliminary trial was repeated until the subject conducted it successfully twice. The trials were introduced in order to let the subject experience manipulation of the button and to implicitly represent the standard duration of $10 \mathrm{~s}$ to the subject. Then the experimenter returned the runner to the starting point, told the subject that the boy always started from that point, and closed the cover. Next the experimenter instructed him as follows. "This time you can not see the walking boy. Continue to push the button until you guess the boy just enters the house. Try to enter the boy just into the house. Start to push the button." The duration while the subject was pushing it, that is, the response duration, was measured by the electric stopwatch. After the subject stopped pushing the button, the experi- menter opened the cover to give a visual feedback in the form of spatial interval between the boy and the house and gave him a verbal feedback, such as, "Too short. On your next turn continue to push the button longer in order to just enter the boy into the house." (when the response duration was shorter than $5 \mathrm{~s}$ ), "A little too short." (when it was between 5 and 9 s), "Good. The boy has just entered into the house." (when it was between 9 and 11 s), "A little too long." (when it was between 11 and $15 \mathrm{~s}$ ), or "Too long. On your next turn stop pushing the button sooner in order to just enter the boy into the house." (when it was longer than $15 \mathrm{~s}$ ). After the informational feedbacks the experimenter closed the cover, returned the runner to the starting point, and began the next trial in the same way. If the subject continued to push the button for more than $30 \mathrm{~s}$ the experimenter told him to stop. In this case his response duration was recorded as $30 \mathrm{~s}$. Such very long response durations were rarely observed.

The criterion of acquisition, which was determined by referring to results of Matsuda, Matsuda, and Miyazaki (1980) and Matsuda, Miyazaki, and Matsuda (1981, 1982), was set as two appearances of response durations between 9 and $11 \mathrm{~s}$, not necessarily successive. When the subject could not reach the criterion within 20 trials, the acquisition was attempted again on the next day in the same way. If he could not reach the criterion within 20 trials again, he was classified as a unsuccessful subject. At any time when the subject was unwilling to continue trials, the experiment was terminated and he was classified as an unsuccessful subject.

The experimental session was repeated several times at intervals of about six months for the same subjects.

Subjects. Thirty one young children served as subjects. Ten of them (Group 1), which consisted of six males and four females, repeated the experimental session 
Table 1

Mean ages in year and month of subjects of Group 1 and Group 2 (in parentheses, ranges)

\begin{tabular}{|c|c|c|c|c|c|c|c|}
\hline Session & 1 & 2 & 3 & 4 & 5 & 6 & 7 \\
\hline Group I & $3: 8(3: 1-4: 0)$ & $4: 2$ & $4: 7$ & $5: 2$ & $5: 7$ & $6: 3$ & $6: 6$ \\
\hline Group 2 & - & - & $4: 6(4: 2-5: 0)$ & $5: 1$ & $5: 6$ & $6: 1$ & $6: 5$ \\
\hline
\end{tabular}

seven times and the others (Group 2), which consisted of 13 males and eight females, did it five times (see Table 1).

\section{Results}

Attitude and number of trials. Figure 2 shows changes of number of trials for each subject. All four unsuccessful children in the first session failed not because they could not reach the criterion of learning within 20 trials in two days, but because they could not perform the experiment. They showed no interest in the experiment, had no will to conduct it, had no patience with repeating trials, and/or could not push the bution continuously but only intermittently. In all the other unsuccessful cases, subjects could carry out the experiment but could not reach the criterion. Generally children of three years old showed little interest in the experiment and were not cooperative with the experimenter. At four years old, most of them began to show interest and cooperation. At five or six years old, some children were often willing to take part in the experiment and showed strong desire to do their tasks well. But depending on the child or on the session, even these children sometimes showed little interest in the experiment.

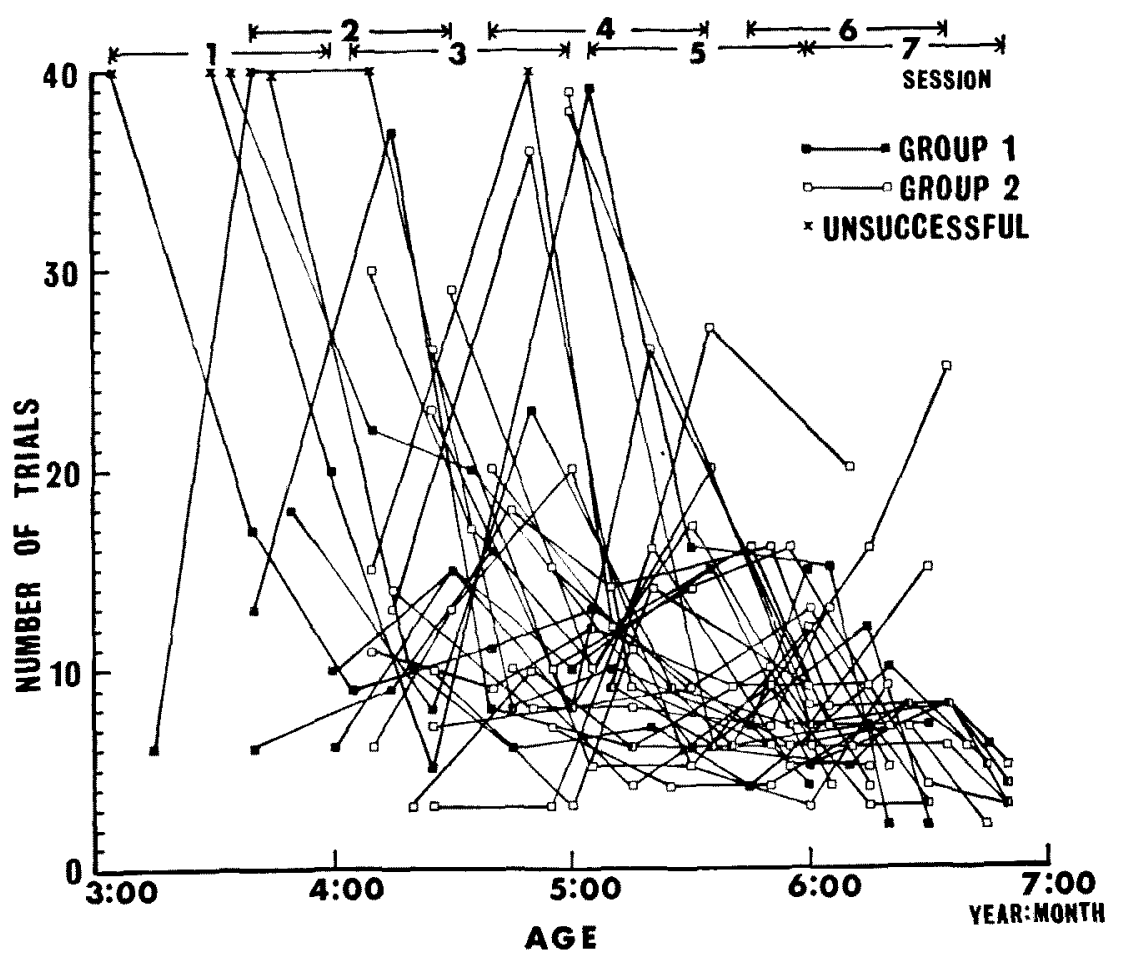

Fig. 2. Number of trials for each child to reach the criterion of learning from session to session. 
Table 2

Mean numbers of trials, their $S D$ to the criterion of learning and results of $F$ tests

\begin{tabular}{|c|c|c|c|c|c|c|c|c|c|}
\hline Session & & 1 & 2 & 3 & 4 & 5 & 6 & 7 & $F$ \\
\hline Group 1 & $\bar{Y}$ & 10.6 & 16.8 & 13.0 & 11.8 & 6.2 & 8.4 & 3.6 & 2.46 \\
\hline$(n=5)$ & $S D$ & 5.1 & 11.8 & 6.5 & 5.6 & 0.8 & 2.1 & 1.5 & \\
\hline Group 1 & $\bar{X}$ & - & 17.0 & 11.7 & 14.2 & 8.0 & 8.6 & 3.9 & $4.69^{*}$ \\
\hline$(n=9)$ & $S D$ & - & 8.9 & 6.4 & 10.2 & 4.0 & 3.1 & 2.0 & \\
\hline Group 2 & $\bar{X}$ & - & - & 16.8 & 11.2 & 10.2 & 9.2 & 8.1 & $4.39 *$ \\
\hline$(n=20)$ & $S D$ & - & - & 11.5 & 8.0 & 5.5 & 5.6 & 6.0 & \\
\hline
\end{tabular}

$* p<.05$.

Mean numbers of trials to the criterion and their $S D$ of the five children in Group 1 who always reached the criterion in seven sessions, the nine children in Group 1 who failed in the first session only or in no sessions, and the 20 children in Group 2 who could always reach it in five sessions are shown in Table 2.

Figure 2 and Table 2 mean: (a) Generally the number of trials to the criterion gradually decreased with age. (b) Generally individual differences tended to decrease with age. (c) Intra-individual variation also seemed to decrease with age.

Vincent curve based on difference of $10 \mathrm{~s}$ from response duration. A difference of $10 \mathrm{~s}$

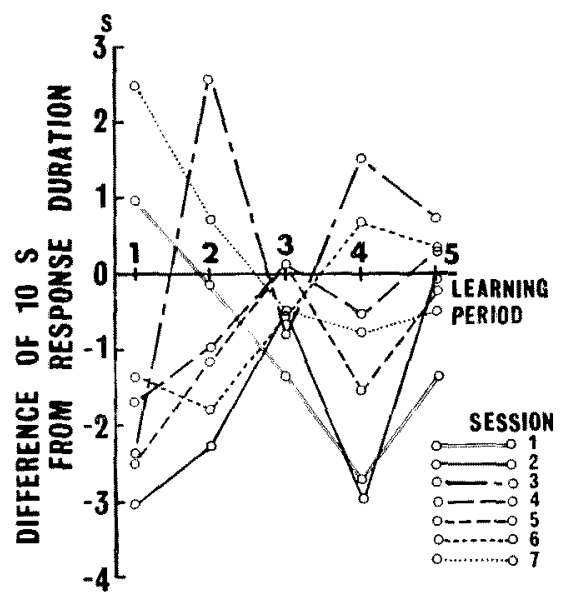

Fig. 3. Mean Vincent curves based on differences of $10 \mathrm{~s}$ from response durations of five children of Group 1 from Session 1 to Session 7. from response duration was calculated in every trial and Vincentized in five periods for every session in each subject. The means of Vincentized learning process for seven sessions of the five children in

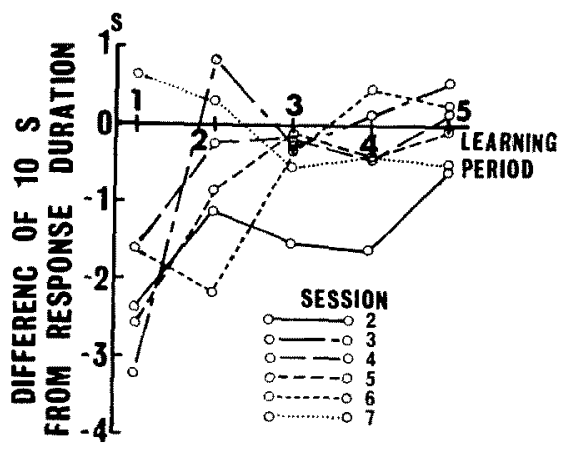

Fig, 4. Mean Vincent curves based on differences of $10 \mathrm{~s}$ from response durations of nine children of Group 1 from Session 2 to Session 7.

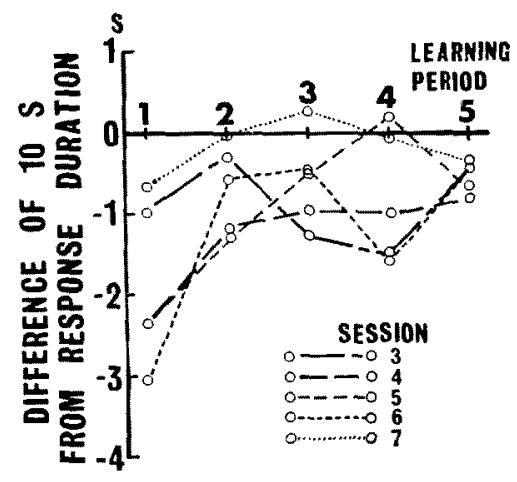

Fig. 5. Mean Vincent curves based on differences of $10 \mathrm{~s}$ from response durations of 20 children of Group 2 from Session 3 to Session 7. 
Group 1, for six sessions of the nine children in Group 1, and for five sessions of the 20 children in Group 2 are shown in Figs. 3, 4, and 5 respectively. From these figures, the associated analyses of variances with two-way classification (Learning Period $\times$ Session) and the results of the individual comparison tests, the following findings were obtained. (a) In Figs. 4 and 5, only effects of Learning Period were statistically significant beyond .05 level $(F=7.02, \quad d f=4 / 32 ; \quad F=3.17, d f=4 / 76$, respectively). That is, differences of $10 \mathrm{~s}$

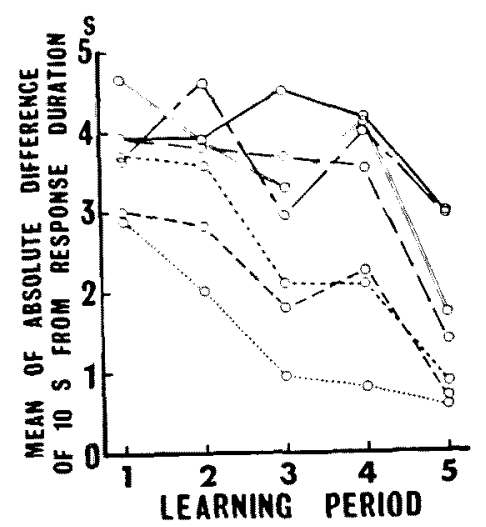

Fig. 6. Mean Vincent curves based on absolute differences of $10 \mathrm{~s}$ from response durations of five children of Group 1 from Session 1 to Session 7. Explanatory remarks are the same as in Fig. 3.

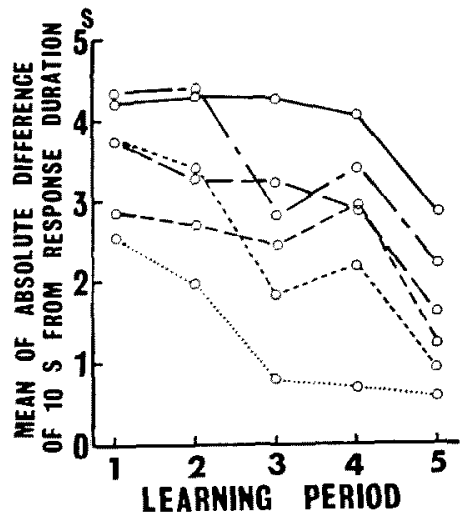

Fig. 7. Mean Vincent curves based on absolute differences of $10 \mathrm{~s}$ from response durations of nine children of Group 1 from Session 2 to Session 7. Explanatory remarks are the same as in Fig. 4. from response duration were large minus values in the first learning period, increased rapidly to small minus values from the first to the second one, and then gradually increased to nearly zero values in the fifth one. (b) In Fig. 3, only the effect of interaction between Learning Period and Session was significant $(F=$ 2.21, $d f=24 / 96)$. This significance did not seem to show any systematic pattern.

Vincent curve based on absolute difference of 10 s from response duration. An absolute difference of $10 \mathrm{~s}$ from response duration was calculated in every trial and Vincentized in five periods for every session in each subject. Means of Vincentized learning process are shown in Figs. 6, 7, and 8 in the same way as Figs. 3,4 , and 5 , and same kinds of analyses were applied to them. The results showed: (a) In all three analyses of variances the main effects of Learning Period were statistically significant beyond .05 level $(F=12.44, d f=4 / 16 ; F=20.92, d f=4 / 32$; $F=24.31, \quad d f=4 / 76$, respectively). The absolute differences decreased gradually through five learning periods. (b) In all three analyses of variances main effects

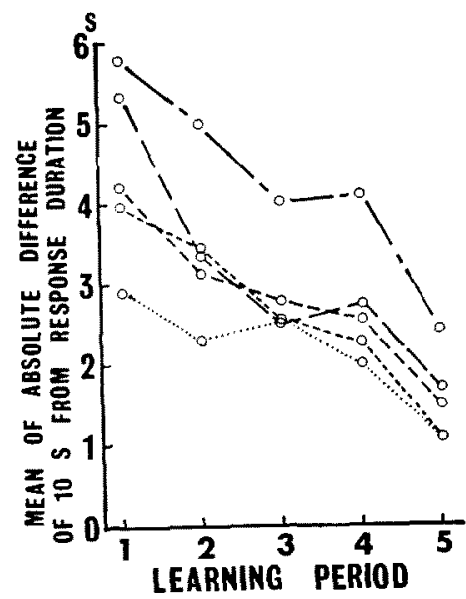

Fig. 8. Mean Vincent curves based on absolute differences of $10 \mathrm{~s}$ from response durations of 20 children of Group 2 from Session 3 to Session 7. Explanatory remarks are the same as in Fig. 5. 
Table 3

Mean ratios of LS, LI, SL, and SS and results of Sign tests between (LS+SL) and $(L L+S S)$ and between $(L S+L L)$ and $(S L+S S)$

\begin{tabular}{|c|c|c|c|c|c|c|c|c|}
\hline Session & & 1 & 2 & 3 & 4 & 5 & 6 & 7 \\
\hline & $n$ & 6 & 9 & 9 & 10 & 10 & 10 & 10 \\
\hline \multirow[t]{10}{*}{ Group 1} & LS & .30 & .27 & .21 & .29 & .22 & .30 & .23 \\
\hline & LL & .03 & .04 & .10 & .03 & .04 & .05 & .06 \\
\hline & SL & .51 & .54 & .55 & .57 & .67 & .53 & .65 \\
\hline & SS & .16 & .34 & .14 & .10 & .07 & .12 & .05 \\
\hline & $\mathrm{LS}+\mathrm{SL}$ & .81 & .81 & .76 & .86 & .89 & .83 & .88 \\
\hline & & * & $*$ & $*$ & $*$ & $*$ & $*$ & $*$ \\
\hline & $\mathrm{LL}+\mathrm{SS}$ & .19 & .18 & .24 & .13 & .11 & .17 & .11 \\
\hline & $\mathrm{LS}+\mathrm{LL}$ & .33 & $\begin{array}{l}.31 \\
*\end{array}$ & .31 & .32 & $\begin{array}{l}.26 \\
*\end{array}$ & .35 & .29 \\
\hline & $\mathrm{SL}+\mathrm{SS}$ & .67 & .68 & .69 & .67 & .74 & .65 & .70 \\
\hline & $n$ & - & - & 21 & 20 & 21 & 21 & 21 \\
\hline \multirow[t]{8}{*}{ Group 2} & LS & - & - & .26 & .22 & .20 & .25 & .40 \\
\hline & LLL & - & - & .01 & .03 & .04 & .04 & .06 \\
\hline & SL & 一 & - & .56 & .62 & .58 & .60 & .48 \\
\hline & SS & - & - & .17 & .13 & .18 & .11 & .06 \\
\hline & $\mathrm{LS}+\mathrm{SL}$ & - & - & $\begin{array}{c}82 \\
*\end{array}$ & $\begin{array}{c}84 \\
*\end{array}$ & $\begin{array}{c}.78 \\
*\end{array}$ & $\begin{array}{c}.85 \\
*\end{array}$ & $\begin{array}{c}.88 \\
*\end{array}$ \\
\hline & $\mathrm{LL}+\mathrm{SS}$ & - & - & .18 & .16 & .22 & .15 & .12 \\
\hline & $\mathrm{LS}+\mathrm{LL}$ & - & - & $\begin{array}{l}.27 \\
*\end{array}$ & .25 & $\begin{array}{l}.24 \\
*\end{array}$ & $\begin{array}{l}.29 \\
*\end{array}$ & .46 \\
\hline & $\mathrm{SL}+\mathrm{SS}$ & - & - & .73 & .75 & .76 & .71 & .54 \\
\hline
\end{tabular}

of Session were statistically significant beyond .05 level $(F=3.66, d f=6 / 24 ; F=$ 11.27, $d f=5 / 40 ; F=8.62, d f=4 / 76$, respectively). Generally, the absolute differences gradually decreased with age. From the 6 th to the 7 th session there were rapid decreases in all cases. (c) In all three analyses of variances interactions between Learning Period and Session were not significant. From (b) and (c), it was suggested that the level of acquisition was lower as the subject was younger, though the criterion of learning was the same through all ages.

Effects of feedback. Such response duration that was shorter (or longer) than the response duration of the previous trial which was longer than $11 \mathrm{~s}$ was designated as LS (or LL). Such response duration that was longer (or shorter) than the response duration of the previous trial which was shorter than $9 \mathrm{~s}$ was designated as SL (or SS). Exclusively high and constant ratios of appearances of LS and SL through sessions are shown in Table 3. It also shows that, in almost all sessions, the response durations shorter than $9 \mathrm{~s}$ appeared twice or three times as often as the response durations longer than $11 \mathrm{~s}$.

An adjustment rate in the $n$th trial (An) was calculated in each subject in each session by the function.

$$
\mathrm{A} n=\left(\mathrm{r}_{n}-\mathrm{r}_{n-1}\right) /\left(10-\mathrm{r}_{n-1}\right)
$$

where $r_{n}$ : Response duration in $s$ in the $n$th trial.

A minus value of $\mathrm{A} n$ means negative adjustment, 0 means no adjustment, a 
Table 4

Means of adjustment rates

$\begin{array}{lrrrrrrrr} & 1 & 2 & 3 & 4 & 5 & 6 & 7 & F \\ \text { Group } 1(n=5) & .85 & .56 & .34 & 1.40 & 1.15 & 1.01 & 1.05 & 2.86^{*} \\ \text { Group 1 }(n=9) & - & .84 & .49 & 1.22 & 1.21 & .92 & 1.02 & 1.69 \\ \text { Group 2 }(n=20) & - & - & .82 & .91 & .73 & 1.00 & 1.10 & 1.35 \\ * \begin{array}{l}* \\ p<.05\end{array} & & & & & & & & \end{array}$

Table 5

Means of absolute difference of each adjustment rate from perfect adjustment rate and results of $F$ tests

\begin{tabular}{lcccccccc}
\hline & 1 & 2 & 3 & 4 & 5 & 6 & 7 & $F$ \\
\hline Group 1 $(n=5)$ & 1.03 & 1.18 & 1.20 & .98 & .72 & .98 & .36 & $3.66^{*}$ \\
Group 1 $(n=9)$ & - & 1.17 & 1.03 & .95 & 1.04 & .89 & .31 & $4.92^{*}$ \\
Group 2 $(n=20)$ & - & - & 1.11 & .85 & .92 & .78 & .81 & $2.21(\boldsymbol{\beta}<.10)$
\end{tabular}

$* p<.05$.

value between 0 and 1 means some positive but insufficient adjustment, 1 means perfect adjustment and a value above 1 means over adjustment. An was not calculated in either the first trial or any where the preceding trial had a response duration between 9 and $11 \mathrm{~s}$. A mean An was calculated for each subject in each session. Table 4 shows the mean of these means. In very young children the mean values were often much larger or much smaller than the perfect adjustment, 1 , but there were no steady developmental tendencies through sessions.

A mean of absolute differences of $\mathrm{An}$ from 1 was calculated for each subject in each session, and are shown in Table 5. Generally these values decreased gradually with age.

\section{Discussion}

In this experiment it was very difficult for children younger than four to learn time estimation. It seemed that they had little interest in the elapse of time. But it may be too early to say that such young children could not learn it in any situations. If an experimental situation which is attractive enough for children under three years old could be prepared, they would perhaps be able to learn it. Weisberg and Tragakis (1967), Weisberg (1970) and Pouthas (1981) showed that a few children aged one to three could in some degree develop behavior adapted to the DRL schedules with 4 to $18 \mathrm{~s}$ pauses, though their temporal regulation was considerably inaccurate.

Our experiments showed that duration estimation was possible at about three years eight months of age. After this age, learning to estimate accurately the duration of $10 \mathrm{~s}$ became gradually and smoothly easier with age, generally speaking. But some 3-year-old children could learn as fast as a normal 6-year-old child. Besides, there were many young children whose number of trials to the criterion of acquisition in an experimental session became much larger as time went on, though these cases decreased with age. These findings showed that the learning did not invariably become easier with age in each individual child. Fluctuations in emotional and volitional factors of the subject, such as his interest in the task, his hope to carry it out well and his perseverance might be causes of the large inter- and intra-individual variations in 
their performances. It seems probable that a decrease in these fluctuations, an increase in ability to concentrate attention and an increase in intellectual ability with age induce progress in the child's learning of duration estimation. Fraisse and Orsini (1955), Orsini and Fraisse (1957, 1959) showed using children aged six to 10 that emotional stability increased with age and was a significant correlate of a better evaluation of duration in the situation of waiting or hurrying.

The progress in the learning was also shown in decreases of absolute differences of the standard duration, $10 \mathrm{~s}$, from response durations with age.

Furthermore, these improvementsscemed not to have any relation to the adequacy of directions in the adjustment of response durations based on the visual and verbal feedbacks. Even the youngest children, in so far as they could learn the duration estimation, lengthened their response durations after the "too short" feedback and shortened them after the "too long" one at a high rate of about 0.8 and this remained stable until seven years old. Mean quantities of adjustment seems also not to be responsible for these progresses in the learning ability with age. Quantities of adjustment were often excessive small or large in very young children but there was little tendency toward perfection with age. Matsuda et al. (1982) showed that the mean quantity of adjustment in a learning process and the number of trials to the criterion in it had little relation. The decrease of adjustment's quantitative fluctuation around the perfect adjustment among trials in a learning process was at least to some extent a cause of progress in the learning ability. Matsuda et al. (1982) found that there were significant positive correlation coefficients between this fluctuation and the number of trials to the criterion. These findings concerning the effects of feedback seem to show that learning processes are qualitatively the same through children of three to six years old and to support the view that for progress in duration estimation learning ability emotional and volitional factors are very important.

In this experiment it seems clear that in early learning period response durations were generally too short and then they lengthened rapidly, though a few 3-yearold children sometimes showed very long response durations at first. Such short responses appeared at a rate of about 0.7 in all sessions. The method used in this experiment is very similar to the method of reproduction, in view of the non use of conventional time units and the operative production of duration by the subject. Actually in the reproduction method, Crowder and Hohle (1970), Matsuda (1965a, b), and Matsuda and Matsuda $(1974,1976)$ showed that reproduced durations were generally too short in a greater degree as the subject was younger. On the other hand, Fraisse and Orsini (1958) and Orsini (1958) had results in which too long reproduced intervals for $30 \mathrm{~s}$ in the reproduction method appeared more often as the subject, from $5 \frac{1}{2}$ to $10 \frac{1}{2}$ years old, was younger and these intervals decreased rapidly during 10 trials with feedbacks. Their results are therefore just the opposite of those of this experiment in length of estimated time at first learning attemps. Causes of the contradiction seem not to lie in differences in the method of time estimation, that is, the reproduction method and the modified response duration schedule. A reasonable cause might be in the difference of the style of the subject's response. In this experiment the subject was pushing a button while he was producing his estimated duration, but in their experiments the subject pushed a button to indicate the end of his estimated duration. The young child may often have little interest in the elapse of time, as shown in the present experiment. If the subject were uninterested in the time estimation, he might stop pushing the button too soon 
or continue no pushing it for too long. Effects of the differences in styles will be examined in the near future.

\section{References}

Axel, B. 1924 Estimation of time. Archives of Psychology, 12 (74), 1-77.

Catania, A.C. 1970 Reinforcement schedules and psychophysical judgments. In W.N. Schoenfeld (Ed.), The theory of reinforcement schedules. New York: Appleton-Century-Crofts. Pp. 1-42.

Crawford, M.L.J., \& Thor, D. H. 1967 Time perception in children in the absence of external temporal synchronizers. Acta Psychologica, 26, $182-188$

Crowder, A.M.H., \& Hohle, R. H. 1970 Time estimation by young children with and without informational feedback. Joumal of Experimental Child Psychology, 10, 295-307.

Flückiger, M. 1975 Comparaisons des durées. Psychogénèses des perceptions de séquences sonores. Archives of Psychology, 63 (170), 1-69.

Fraisse, P., \& Orsini, F, 1955 Etude expérimentale des conduites temporelles. I. L'attente. L'Année Psychologique, 55, 27-39.

Fraisse, P., \& Orsini, F. 1958 Etude expérimentale des conduites temporelles. III. Etude génétique de l'estimation de la durée. L'Année Psychologique, 58, 1-6.

Friedman, E. R. 1977 Judgments of time intervals by young children. Perceptual and Motor Skills, 45, 715-720.

Kawahara, A., \& Miyazaki, H. 1980 Production of time-space memory measuring apparatus. Bulletin of the Japan Society of Industrial and Technical Education, 22, 157-160. (In Japanese)

Matsuda, F. 1965a Development of time estimation: I. Effects of degree of unity in verbal auditory stimulus. Japanese Journal of Psychology, 36, 169-177. (In Japanese with English summary)

Matsuda, F. 1965b Development of time estimation. II. Effects of frequency of sounds given during standard time. Japanese Journal of Psychology, 36, 285-294. (In Japanese with English summary)

Matsuda, F., \& Matsuda, M. 1974 Effects of frequency of intermittent stimuli on time estimation in children and in adults: I-Sounds and lights-. Psychologia, 17, 206-212.

Matsuda, F, \& Matsuda, M. 1976 Effects of frequency of infermittent stimuli on time estimation in children and in adults: II. Psychologia, 19, 11-22.

Matsuda, F., Matsuda, M., \& Miyazaki, H. 1980 Acquisition and extinction in duration estimation. Bulletin of the Facully of Home Economics, Hiroshima Ifomen's University, 15, 63-70. (In Japanese with English summary)

Matsuda, F., Miyazaki, H., \& Matsuda, M. 1981 A longitudinal study on learning of duration cstimation in young children. Bulletin of the Faculty of Home Economics, Hiroshima Women's Universit), 16, 87-99. (In Japanese with English summary)

Matsuda, F., Miyazaki, H., \& Matsuda, M. 1982 Effects of feedback on learning process of duration estimation in young children. Bulletin of the Faculty of Home Economics, Hiroshima Women's University, 18, 173-181. (In Japanese with English summary)

Orsini, F. 1958 Etude expérimentale des conduites temporelles. IV. Effet de l'apprentissage sur la reproduction d'une durée chez l'enfant et chez l'adulte. L'Année Psychologique, 58, 339-345.

Orsini, F., \& Fraisse, P. 1957 Etudes des conduites temporelles. II. Etude génétique de l'attente. L'Année Psychologique, 57, 359-365.

Orsini, F., \& Fraisse, P. 1959 Etude expérimentale des conduites temporelles. La précipitation. Psychologie Franfaise, 4, 117-126.

Pouthas, V. 1981 Adaptation à la durée chez l'enfant de 2 a 5 ans. L'Année Psychologique, 81, 33-50.

Richards, M. 1964 Time estimates measured by reproduction. Perceptual and Motor Skills, 18, 929-943.

Smythe, E. J., \& Goldstone, S. 1957 The time sense: A normative, genetic study of the development of time perception. Perceptual and Motor Skills, 7, 49-59.

Stein, N., \& Landis, R. 1978 Effects of age and collateral behavior on temporally disciminated performance of children. Perceptual and Motor Skills, 47, 87-94.

Weisberg, P. 1970 Effects of reinforcement history of timing (DRL) performance in young children. Journal of Experimental Child Psychology, 9, 348-362.

Weisberg, P., \& Tragakis, C.J. 1967 Analyses of DRL behavior in young children. Psychological Reports, 21, 709-715.

(Received Nov. 15, 1982; accepted Sept. 11, 1983) 